Paideusis

\title{
Assessing Expert Claims: Critical Thinking and the Appeal to Authority
}

\section{Mark E. Battersby}

Volume 6, Number 2, 1993

URI: https://id.erudit.org/iderudit/1073304ar

DOI: https://doi.org/10.7202/1073304ar

See table of contents

Publisher(s)

Canadian Philosophy of Education Society

ISSN

0838-4517 (print)

1916-0348 (digital)

Explore this journal

Cite this article

Battersby, M. (1993). Assessing Expert Claims: Critical Thinking and the Appeal to Authority. Paideusis, 6(2), 5-16. https://doi.org/10.7202/1073304ar viewed online.

https://apropos.erudit.org/en/users/policy-on-use/ 


\section{Assessing Expert Claims: Critical Thinking and the Appeal to Authority}

\section{Mark E. Battersby, Capilano College}

Much of our understanding and knowledge of the world is based on the authoritative pronouncements of experts. Both our scientific and historical understanding is grounded in this way. Think of germ theory, astronomy, plate techtonics, ancient history, dinosaurs, the origin of humans; it does not take much reflection to see that most of our understanding of the world is, in fact, grounded on information supplied and warranted by experts. Given how much of our knowledge has this basis, one would think that epistemologists would have given detailed consideration to the issue of appeal to scientific and other intellectual authority. But appeals to authority and the role that authority plays in knowledge have received little attention in modern philosophy. Indeed, philosophers generally have been opposed to such appeals since the birth of Western philosophy.

Greek philosophy distinguished itself from Greek theology by rejecting appeals to authority (the wisdom of the ancients or the oracle's supply of the word of god) as the primary basis of knowledge and replacing those appeals with appeals to observation and reason as the basis of knowledge. Philosophy in many ways began with rejection of authoritative pronouncements and, when philosophy revived in the seventeenth century, the aversion to authority reappeared. By rejecting the authority of both Aristotle and the church, Descartes, Bacon, and Locke helped pave the way for modern science. These authors all rejected the appeal to any authority and, in doing so, marked the beginning of modern philosophy with its emphasis on individual confirmation of claims.

As a result of this history, most contemporary introductions to epistemology do not even mention the issue of appeals to experts and authority, and there is little in contemporary epistemological literature that concerns itself with this topic. ${ }^{1}$ But one might expect critical thinking, with its concern for the practical needs of knowledge assessment, would devote considerably more attention to appeals to authority. In fact, most critical thinking texts do not even refer to appeals to authority and only a few texts give the subject significant treatment; none of these treatments is adequate, in part, perhaps because there is no epistemological theory on which to base such a treatment. Of those that do treat such appeals, many give appeals a definite secondary and necessary evil status. For example, Walton states:

generally speaking we only appeal to experts if, in fact, it may be too expensive or otherwise difficult for us to have direct evidence. That is why we may legitimately appeal to experts as a secondary source of subjective knowledge when we have to make a decision. ${ }^{2}$

There are at least two reasons for such neglect. One is the philosophical tradition mentioned above, but perhaps the most important reason is that appeals to authority seem to violate the spirit of critical thinking. After all, was not critical thinking meant as an antidote to students' all-too-willing acceptance of the authoritative pronouncements of teachers and textbooks? Are we not supposed to be teaching students to question, not just accept authority? Indeed, the very Latin name for the traditional fallacy of appealing to authority ad vercun- 
diam means literally the appeal to modesty or shyness. It is not too mistaken to interpret this as inappropriate deference. ${ }^{3}$ And surely it is just such deference that we as teachers of critical thinking wish to eliminate. As Locke stated in An Essay Concerning Human Understanding:

For I think, we may as rationally hope to see with other Men's Eyes, as to know by other Men's Understandings. So much as we our selves consider and comprehend of Truth and Reason, so much we possess of real and true Knowledge. The floating of other Men's Opinions in our brains makes us not one jot the more knowing, though they happen to be true. What in them was Science, in us but Opiniatrety, whiles we give up our Assent only to reverend Names, and do not as they did, employ our own Reason to understand those Truths, which gave them reputation. . . In the Sciences, every one has so much, as he really knows and comprehends: What he believes only, and takes upon trust, are but shreds; which however well in the whole piece, makes no considerable addition to his stock, who gathers them, Such borrowed Wealth, like Fairymoney, though it were Gold in the hand from which he received it, will be but Leaves and Dust when it comes to use. ${ }^{4}$

Plausible as this objection is, it obviously cannot be allowed to stand. Too much of our knowledge is based on just such condemned sources. While only a few contemporary philosophers have noted this and attempted to outline the significance that authoritative appeals have to epistemology, John Hardwig, has shown that even physicists are heavily dependent on the expertise of their fellow physicists in order to develop and understand their own experiments. Hardwig points out that it is not untypical for thirty to fifty physicists to be involved in a major experiment because only with that range of expertise can the data be assembled and understood. And the final result relies for its credibility on the trust and respect that the participating physicists bave for each other, since no single individual is competent to carry out more than a few of the operations involved.

Given the import of appeals to authority, it seems obvious that we should have a proper theory of such appeals. This theory should have implications for epistemology generally, and to critical thinking in particular, since much of what a critical thinker must do involves assessing the claims of genuine and would-be experts. A critical but appropriate approach to authoritative appeals must replace not only deference but also the narrow model used in contemporary critical thinking texts.

To develop an analysis of appeal to authority that could be used by the teacher of critical thinking, I will first critique the typical model of proper appeal to authority used in critical thinking texts, contrast this model with the model suggested by court proceedings involving experts, sketch an alternative conception of knowledge that places appeals to authority in the appropriate central role and, finally, show how all this can be used to illuminate and improve the teaching of critical thinking. A task of such magnitude is, of course, impossible in this limited space and as a result many important issues will receive short shrift. My hope is at least to sketch the outline of a new approach to authoritative appeals and its implications for critical thinking. 


\section{Critique of the Traditional Approach}

The typical analysis of arguments involving appeals to authority is as follows:

A has asserted $P$.

$P$ falls within area of knowledge $K$.

$A$ is a recognized expert regarding $K$.

Therefore, $P$ is acceptable. 5

Some authors, including Govier and Blair and Johnson, also point out that additional considerations surrounding such an appeal include:

1. The expert must not be in a position of bias;

2. The experts on $K$ agree about $P$;

3. The more eminent the expert the stronger the appeal.

\section{Difficulties with this Approach}

Before exploring the difficulties with this approach, I must make a rough and, I hope, uncontroversial distinction between particular and general judgements. By this distinction, $I$ have in mind the difference exemplified by an engineer, on one hand, giving her view on why a bridge collapsed (a particular judgement) and, on the other, offering the physical and engineering theory of stress (general judgement). The reason for this distinction is that an expert's expertise is used in different ways in the two kinds of judgements.

In the typical complex particular judgement, the expert is called upon to use her explicit and implicit understanding of the issue. In the particular judgement, there is more reliance on the expert's individual expertise, experience, and even eminence in her field. Whereas, in the general judgement, we are relying on the expert's knowledge of views held in her field, her responsibility in enunciating this knowledge is to convey the wisdom of the discipline, not her personal views. In the case of general judgement, the expert is primarily a vehicle for transmitting the views developed and confirmed in her discipline. Significantly, this is characteristic of the situation we find ourselves in as teachers: we essentially convey knowledge of our discipline.

If, indeed, the expert functions differently in the two kinds of judgement, then any adequate model of appeal to authority must recognize this distinction. But no model I have found does so. Those models that emphasize the eminence of the authority as part of the criteria of assessment seem to be based on the particular judgement model. Those that only mention the importance of the consensus of the expert's discipline seem concerned only with the general claim.

In critical thinking we are mainly concerned with the expert as a source of general claims-for example, the nature of solar system and the causes of cancer. For this reason we are concerned with the expert as representative of her discipline rather than as someone using her expertise to make a particular judgement. In this paper, I will only discuss appeals to authority in relation to general claims. There remains much to be said about particular claims, especially in value-oriented disciplines and everyday decisions.

What then are the implications of observing that the expert is primarily a vehicle for transmitting knowledge of her discipline rather than an individual source of knowledge? First, we must abandon the model of the expert as 
someone who can give us knowledge simply by telling us her view. We listen to experts because they are representatives of a body of knowledge. That is why there should not be expert disagreement in the fields to which we are appealing: we are not really interested in the expert's personal opinion but rather that of her discipline. If there is no consensus in the discipline, then the discipline has in a sense nothing to (univocally) say. Only by viewing the expert as a discipline spokesperson can we understand the requirements of appeals to authority, deal with Locke's objection, and even make sense of our role as teachers of critical thinking.

\section{Expert Disagreement}

One thing should alert us to the weakness of the traditional analysis. In this approach, disagreement among experts renders appeals to authority fallacious. But many of the interesting cases one deals with will involve conflict among experts. What about conflicting opinions from doctors, disagreement among experts about the proper treatment of AIDS, or the causes of cancer? The courts must deal with expert conflict as a matter of course. Are all such conflicts to be deemed sufficient ground for dismissing the expert opinions presented? This seems much too drastic to be sensible. ${ }^{6}$

\section{Legal Approaches to the Use of Experts 7}

Rather than dismiss competing expert claims, the courts insist that the expert not just deliver her opinion but also explain her reasoning. Given the model I am criticizing, this requirement would seem surprising. Should one not just accept the claim if the expert has the relevant credentials? But the courts are faced with conflicts among experts and feel too accountable to simply bow to the authority of the expert.

Locke's objection would be taken quite seriously by the courts. They cannot use mere "opiniatrety" because they are responsible for legal decisions. The courts' compromise is to take expert opinion, but require that the expert explain herself so that the court can both judge (where there is conflict or just doubt) and understand.

Because courts have to deal with conflicting testimony, they have to make a legal judgment on the merits of the expert's argument. They assess the clarity, methods, apparent bias, and plausibility of competing experts' explanations to decide how to weigh the opinions. Experts in the courtroom are an exception to the general rule that the courts engage in reasoning and the witnesses are merely to report what they saw, heard, etc. But because the experts' opinions are based on reasoning from the facts and not from merely asserting them, the courts reserve the right to examine this reasoning. In so doing, they are not restricted to considering only character questions when evaluating testimony and argument but rather use all available evidence to determine the weight to be given to experts' claims. It seems to me that this approach is exactly the right strategy for any rational person to take. ${ }^{8}$

The procedures of the court should show us that the sharp distinction made between testimony and angument is untenable. We need the expert's credibility before we will believe her arguments, but her credibility is not the sole basis of our appraisal. Argument assessment is to some extent discipline- 
specific and, for this reason, we need the assurance of the expert that this line of reasoning and these types of inferences are respected within her field. We need her reassurance that she is not ignoring counter-evidence or contrary opinions within her field. We also must, of course, comprehend and be persuaded by the evidence and explanations. But even allowing our understanding to be moved by the expert's account is itself an act of trust in her authority.

The crucial point for critical thinking is that appeals to authority must involve justification and explanation. What the Lockean model (and the contemporary one given above) ignores is the expert's obligation to supply justification for her position. The model cannot tolerate disagreement among experts because it provides virtually no method of adjudication. This point is the most crucial objection and indeed is the basis of Locke's criticism: the model seems to require just too much mindless trust in the experts. By not requiring that the expert provide any argument, explanation, or justification for her assertion, the model leaves the believer in a hopeless state of acute epistemic dependence. ${ }^{9}$ It probably also leaves the layperson who accepts the claim with no real understanding of the claim she now believes.

\section{Appeal to Authority and Education}

To the extent that education consists simply in telling without justification and explanation, it, too, leaves the student in a state of epistemic dependence (to say nothing of ignorance!). But without trust in authority, there would be no successful transmission of knowledge. For example, in part we believe in the biological theory of germs because it is explained to us in a manner that makes sense. It is also supplied and supported by a well-established discipline. Surely we all now know that it is quite easy to make a plausible explanation of some phenomenon that just does not stand up to careful empirical or dialectical attention. The only way we know that the plausible explanations that are supplied to us by our teachers are, indeed, correct (not just plausible) is because of the credibility of the source.

Without the explanation, we find ourselves in the position of saying, "I don't know, but they say...." When we fail to give any argument that supports the claim (that it is based on these tests or fits with that existing understanding), we are admitting that we do not really know the claim to be true, only that we have some authoritative reason to believe it. This admission is the weakest of all appeals to authority and should hardly be our paradigm.

Legitimating the demand for explanation and justification is, therefore, the key to the proper use of authority. It provides for understanding and the opportunity for the layperson to adjudicate between competing expert claims or claims in fields that are not characterized by consensus. This foundation opens the door to using (with appropriate scepticism) expertise in value-laden disciplines.

\section{Appeal to Authority in Value-Laden Fields}

Most authors exclude appeal to authority in value-laden disciplines. But what about great moralists, literary critics, and aestheticians? Is there no place for appeal to authority in these cases? Perhaps the appeals are weaker, but are they fallacious? Are these all to be ignored? Lacking a theory justifying the rejection of such appeals to authority, it is hard to see what the rejection of 
appeals to authority in disciplines including art criticism and philosophy is based on. There certainly is expertise among art and literary critics, architects and town planners, though these fields are rife with appeals to value. Let me suggest briefly that any discipline qua discipline must have standards that are more or less consensually shared. Otherwise there would be no discipline, no way to justify awarding degrees, grades, and such. To the extent that there is some underlying consensus, a powerful case at least can be made for legitimate appeals to consensually held views. Again, this approach requires much development.

\section{Eminence}

My last criticism of the standard model concerns the claim that the more eminent the expert, the more successful the appeal. In most general cases, someone with adequate and appropriate knowledge of a field-such as a local professor-is all we need. It is not her expertise that we need so much as her competence to transmit the knowledge of the discipline. In some cases, there may be problems in appealing to an eminent expert for she may be vulnerable to, or suspected of, bias because of her involvement with a leading or even a dissenting theory. Since we usually need the expert to convey knowledge of the discipline, eminence is not a necessary criterion.

The critique developed above is based on the view that a large part of knowledge is grounded not in observation or intuition but in expert consensus. I wish to make few remarks in support of this position. Whatever may be its theoretical problems, it seems to me unquestionable that the layperson has justified belief in most theoretical propositions when she knows these beliefs to be supported by the relevant discipline and has some minimal grip on the justification that supports them. I will call the view that knowledge is grounded in expert consensus the "social theory of knowledge."

\section{The Social Theory of Knowledge}

While various philosophers since Descartes have attempted to limit the sceptical effect of his approach, few have abandoned the essentially individualistic approach that led to the sceptical result. But when we start noticing which claims people typically say they "know," we can easily observe that these include theoretical, general claims of their scientific culture, not just claims about their own experience. For example, the view of the solar system as involving planets that revolve around the sun-indeed, the picture of the solar system that appears in every popular text on the subject-is a view that most people would rightly claim to know to be true. We also know that the material world is made of atoms that combine into molecules, that bacteria and viruses are the causes of diseases, that burning is a form of rapid oxidation, and the list goes on. Not everyone may claim to know these points, but that is a testimony to their ignorance, not their insight into the true nature of knowledge. And how many of us know these facts in any great depth? In particular, how many of us could prove or even cite the observations that prove them? Are we rendered into a state of mere "opiniatrety" as a result?

I think the answer is clearly no. In fact, as Hardwig, Walsh, Lehrer and others have pointed out science itself comprises mutual dependence and trust 
among its members. Those who have shown that science is inadequately grounded in experimental evidence are correct, but this position does not have to lead to relativism. Rather, it underlines the crucial role that collective evaluation plays in the establishment of a scientific theory. And the success of this social process is what justifies the layperson's confidence in the results, and justifies appealing to expert pronouncements. There is much more to say here, ${ }^{10}$ but $I$ now wish to turn to the practical implications of my view.

\section{Teaching and the Social Theory of Knowledge}

The primary job of a teacher is to transmit knowledge. The teacher is not in class to share her beliefs and opinions, though, of course, we all do. (And we do so rightly, but that is not our main job.) We are the representatives of our disciplines and in the classroom we pass on to our students what the discipline believes is both important and true. This is seen most easily, perhaps, in those disciplines where course content is clearly delineated such as calculus and firstyear physics, but it is similar for English 100 or even critical thinking courses. Since I am writing for critical thinking instructors and since critical thinking is my area of expertise, let me begin to illustrate my point by discussing the role of a critical thinking instructor.

It is one of the curious aspects of the discipline of critical thinking that the deeper epistemological worries of philosophers seldom surface in the texts or in class. Teaching introductory philosophy is always a case of teaching "on the one hand. . .but on the other. . ." In critical thinking classes, however, we unabashedly teach students the norms of reasoning. And we are, I would certainly argue, quite justified in doing so. Of course, we do not teach that our particular analysis of a piece of text is a case of knowledge, but we do teach that the "following considerations should be taken into account when assessing a claim based on testimony." We do not teach these epistemological norms as mere beliefs; rather, we teach them as part of the "know-how" of being a critical thinker. This does not, and should not, preclude giving the rationale for the rules, but these are rules which a student must know in order to be able to do analysis and arrive at reasonable beliefs about claims and arguments. We ask ourselves as critical thinking instructors, "What basic rules and skills does a student need to know in order to evaluate arguments?" Note that we ask what a student needs to "know," not "needs to believe." Indeed, if we ask that question, it sounds as if we are involved in manipulation. As teachers, we only have a right to transmit what we know. We can, of course, tell our students what we believe and why, but we do not teach, instruct, and test them about our "beliefs." And how do we distinguish the justifiably teachable and testable from our other beliefs? Is it not our perception of the consensus of our discipline that guides us? In teaching critical thinking, as in logic and mathematics, we are operating in an area of significant consensus within a discipline and are authorized, therefore, to teach "one-handed" philosophy; that is, to teach the accepted theories as knowledge. In those cases where our own beliefs differ from our perception of the consensus, we are obligated to alert our students and to make this recognition govern our procedures. 


\section{Implications for Teaching Critical Thinking}

If scientific, historical, and, perhaps, all theoretical knowledge is, indeed, grounded in collective decision-procedures, especially those of academic peer review, what are the implications for teaching critical thinking students about authority?

1. The assessment of authority must be given a more central place in our textbooks. Equally importantly, it must not be understood (as it typically is) as simply an appeal to the claims of an individual with appropriate expertise, but rather as an appeal to the claims supported by the consensus of the discipline for, in cases of general judgements, the expert is primarily a well-informed reporter.

2. We must recognize that most knowledge and information is going to be supplied to our students and ourselves by experts. As a result, the responsibility for the critical thinker becomes principally learning how to assess sources and expert claims. The student must be taught how to do this, and, indeed, we as teachers of critical thinking must think more about this ourselves.

As Hardwig points out, when assessing experts, we must frequently resort to a variety of ad hominem considerations. To the extent this is true, we should supply our students with the methods of appropriate ad hominems-for example, understanding the sociology of the disciplines, reading citation indexes, identifying credible journals, and detecting when experts are going beyond "authorized" claims. We need to teach about the kind of blindness that is apt to infect experts, and about the fallibility and limitations of scientific claims. We must teach our students their legitimate right to question experts and how to assess their answers. It is easy enough to promote the slogan "Question authority!' but, if we do not also give students the norms to assess the answers and defend the questions, they will lack the rational confidence necessary for this questioning to be productive. We all know how to do some of this, but much more could be done in developing the rules of thumb that we could pass on to our students.

3. The role of consensus must be explained and emphasized. We should explain to our students why consensus or the lack of it is so relevant to assessing appeals to authority.

4. A new model of appeal to authority that emphasizes the importance of the expert providing explanation and justification must be taught. Below is a preliminary sketch of a new model of appeal to authority. Here I have focused on only one type of claim: an empirical/general claim. Similar models would be needed for all four possible types (including empirical/particular, value/general, and value/particular).

A says $P$.

$P$ is in A's area of competence.

Is P's claim particular or general?

If the claim is empirical/general, then we can ask whether the nature of A's discipline is fractured or homogeneous?

If it is homogeneous, then

Is $P$ a well-accepted claim in A's discipline? 
If yes,

Why is $P$ well-accepted?

If the explanation is plausible and intelligible, then $P$ can be considered knowledge.

If no, why does $A$ believe $P$ ?

Intrinsic plausibility of claim.

The more implausible, the more evidence necessary.

Is the justification plausible?

Are the reasons for rejection of other positions plausible?

What are A's credentials relative to the discipline?

What are A's likely biases?

Prestige of $A$.

If discipline is fractured, then, weigh crediting of $P$ according to:

Nature of discipline.

Intrinsic plausibility of claim.

The more implausible, the more evidence necessary.

Plausibility of the explanation.

Reasons for rejection other positions.

Clarity versus vagueness.

Reported depth of evidence.

Apparent objectivity of A.

Prestige of A.

Is the expert's claim scrutinized by her peers? ${ }^{11}$

The model obviously needs refinement because the situation is more complicated then the model suggests and, to be useful, the model must actually be simpler in its outline. But let me offer a few remarks. Note that appeals to authority in disciplines that are fractured and/or without consensus are really quite different from appeals to views supported by discipline consensus. In the former, the layperson must base her judgement much more on her own assessment of the arguments than on the weight of the expert. And, of course, in these areas, no one can claim knowledge, only justified belief. Disciplines themselves may be said to have degrees of credibility. ${ }^{12}$

\section{The Implication for Teaching in Other Disciplines}

We are far more frequently knowledge consumers than we are producers. Students taking introductory courses in a discipline are unlikely to ever be producers in this area. They should be taught not only the current understandings but also how to be competent consumers of the research in the area (for example, reputable journals to read, methods of assessment, appropriate sample size, time required for results to be evaluated and accepted)-basically, a discipline-specific sociology of knowledge. This is desirable, not because this is the "game you play in biology," but because this is the way biological theories and evidence are validated; this is the way knowledge is produced in this field.

I read with some interest that Mark Weinstein at the Montclair Institute for Critical Thinking appears to be trying to get faculty to develop and articulate 
their discipline's authoritative structure under the rubric of epistemology of the disciplines. While I am not saying that epistemology is sociology (and I am not arguing that Weinstein is saying this either), I do want to say that the "authority" structure of a discipline is certainly relevant for assessing claims and for understanding which claims deserve rational belief. For the non-expert, such information may be some of the most relevant information she can possess in assessing an expert's claims.

\section{Summary}

The role of authority in supporting knowledge has been insufficiently articulated both in the discipline of epistemology and in the teaching of critical thinking. But because critical thinking instruction aims to give students guidance in the everyday assessment of claims, it is absolutely crucial that use of authorities and their evaluation be taught. The goal of introductory postsecondary education should be to equip students to be rational "information consumers"-individuals who can think critically about and use intelligently all sorts of claims, but especially those supplied by the intellectual authorities of the culture. Whether as citizen, businessperson, or intellectual, a rational person's understanding of the world is constituted largely by authoritative knowledge. The critical thinker must be proficient in the use and evaluation of such knowledge as well as understanding the delicate art of rational trust and appropriate scepticism.

\section{Notes}

${ }^{1}$ The articles by Walsh, Stitch and Nisbett, Hardwig, and Lehrer, and to some extent the book by Welbourne are the only references that I have been able to find. Some of the work in philosophy of science outlining the social nature of justification is related. Unfortunately, most of this literature is relativistic and contrary to the thrust of this paper.

${ }^{2}$ D.N. Walton, Informal Fallacies: Toward a Theory of Argument Criticisms (Amsterdam: J. Benjamins Publishing Company, 1987), 187. I do not know what Walton means by "subjective knowledge"-though it sounds pejorative.

${ }^{3}$ C. Hamblin, Fallacies (London: Methuen, 1970), 43.

${ }^{4}$ John Locke, An Essay Concerning Human Understanding, 1, iv, 23, quoted in Michael Welbourne, The Community of Knowledge (Aberdeen: Aberdeen University Press, 1986), 49.

${ }^{5}$ Trudy Govier, A Practical Study of Argument, 2nd edition (Belmont, Ca: Wadsworth, 1988), 83.

6There has been an effort to deal with expert conflict by Walton (1987) based on the work on plausible reasoning by $\mathbf{N}$. Rescher. This approach is fairly technical and has not seen implementation in any textbooks. But it is also based on the notion of total evidence, though it uses a method for choosing the maximum consistent subset of information. Necessarily this approach just eliminates one expert's opinion when there is genuine contradiction.

'I owe most of my understanding of the courts' use of scientific information to Imwinkerlried (1987). 
${ }^{8} \mathrm{John}$ Hardwig suggests that the layperson, when confronted with expert disagreement will have to base her decision primarily on ad hominem kinds of considerations because of her inability to assess justifications. There is no question that the assessment of the expert herself (but also the credibility of the discipline-ad disciplinium?-is something a layperson should do. Like a judge, the layperson is also wise to attempt to assess the conflicting justifications using whatever evidence she can gather. This is simply an application of the principle of total evidence.

9 owe this phrase to John Hardwig.

${ }^{10}$ I draw the reader's attention to the articles by Stitch and Nisbett, Walsh, and Lehrer listed in the references.

${ }^{11}$ Another consideration that is sometimes mentioned in the traditional view, and fits nicely with my own theory, is the issue of publicity. It is reasonable to assume that authorities are much more careful in a situation of peer review because they can be taken to task for incorrectly representing the state of the knowledge and the discipline. Given that what we want is accurate reporting, the conditions of publicity are relevant to weighing an expert's claim.

${ }^{12}$ Walsh, for example, mentions philosophy's justified lack of credibility due to its fractious nature.

\section{References}

Black, Max. Critical Thinking: An Introduction to Logic and the Scientific Method. 2nd edition. New York: Prentice Hall, 1952.

Blair, Tony, and Ralph Johnson. "The Recent Development of Informal Logic." In Informal Logic: The First International Symposium, edited by Tony Blair and Ralph Johnson. Inverness, Ca: Edgepress, 1980.

Cederblom, J., and D. Paulsen. Critical Reasoning. Belmont, Ca: Wadsworth, 1982.

Govier, Trudy. A Practical Study of Argument. 2nd edition. Belmont, Ca: Wadsworth, 1988.

Govier, Trudy. Selected Issues in Logic and Communication. Belmont, Ca: Wadsworth, 1987.

Johnson, Ralph, and Tony Blair. Logical Self-Defense. 2nd edition. Toronto: McGraw-Hill Ryerson, 1983.

Hamblin, C. Fallacies. London: Metheun, 1970.

Hardwig, John. 'Epistemic Dependence." In Journal of Philosophy 82(7), 1985: 335-49. Reprinted in Govier with slight modifications as "Relying on Experts."

Imwinkerlried, E., ed. Scientific and Expert Evidence. 2nd edition. New York: Practising Law Institute, 1987.

Lehrer, Keith. "Social Information." In Monist, 9, 1977: 473-87.

Polanyi, Michael, and Harry Prosch. Meaning. Chicago: Chicago University Press, 1975.

Siegel, N.S. Educating Reason: Rationality, Critical Thinking, and Education. New York: Routledge, 1988.

Siegel, N.S. "Rationality and Epistemic Dependence." In Educational Philosophy and Theory, 20(1), 1988: 16. 
Stitch, Stephen P., and Richard E. Nisbett. "Justification and the Psychology of Human Reasoning." In Philosophy of Science, 47, 1980: 188-202.

Waller, Bruce N. Critical Thinking: Consider the Verdict. New York: Prentice Hall, 1988.

Walsh, W.H. "Knowledge in Its Social Setting." In Mind, 80, 1971: 321-36.

Walton, D., and J. Woods. Argument: The Logic of the Fallacies. Toronto: McGraw-Hill Ryerson, 1982.

Walton, D.N. Informal Fallacies: Toward a Theory of Argument Criticisms. Amsterdam: J. Benjamins Publishing Company, 1987.

Walton, D.N. Logical Dialogue Games and Fallacies. Lanham, Maryland: University Press of America, 1984.

Welbourne, Michael. The Community of Knowledge. Aberdeen: Aberdeen University Press, 1986. 